\title{
Design and Analysis of Automobile Bumper with the Capacity of Energy Release
}

\author{
${ }^{1}$ K.Ashok Kumar, ${ }^{2}$ N.Boominathan.ME.,(PhD)., ${ }^{3}$ D.Akilan.MTech \\ ${ }^{I}$ ME-Industrial Safety Engineering Cauvery College of Engineering and Technology \\ Trichy, India \\ ${ }^{2} \mathrm{HOD}$, Industrial Safety Engineering, Cauvery College of Engineering and Technology \\ Trichy, India \\ ${ }^{3}$ Assistant Professor, Mechanical engineering Cauvery College of Engineering and Technology \\ Trichy, India
}

\begin{abstract}
The goal of this work is to mitigate the degree of damage to passengers caused by automobile collisions. Crash phenomena involving road vehicles were investigated for the purpose of developing an impact attenuation design that can withstand speeds higher than the current specified range of up to 4 $\mathrm{km} / \mathrm{h}$ (for a bumper). Different impact attenuation systems in the vehicle were studied with emphasis on the bumper modeling, analysis and design. A mathematical model for a bumper was developed. Simulation of impact of the bumper against a fixed barrier was performed. A passive friction element was introduced into the bumper system to improve on the attenuation of the impact and kinetic energy absorption capacity. A mathematical model of the bumper-damper system was formulated and used to simulate impact phenomena for a $1900 \mathrm{~kg}$ mass moving at a speed of $70 \mathrm{~km} / \mathrm{h}(19.4 \mathrm{~m} / \mathrm{s}), 17.5$ times the speed of a typical design specification. The simulation revealed that the energy absorption capacity of the bumper was improved with the addition of a friction element. Design parameters for the friction damper were extracted from the results of the simulation. The extracted design parameters include stiffness, $k$, and coefficient of the damping, $c$, of the bumper. The use of the results from the simulation in the design of the bumper was pursued with success. Friction damper designs were proposed. Two of these designs were built and used in experiments to verify their effectiveness and to validate the simulation results. The experiments revealed that higher energy absorption could be achieved with the addition of a friction element to traditional bumpers.
\end{abstract}

\section{Introduction}

The rate of motor vehicle accidents globally is alarming and naturally increases as the number of vehicles on the roads increases. The trend in the rate of road accidents is the same in many countries in that it is growing. It is estimated that 1.2 million people are killed in road crashes and nearly 50 million are injured worldwide every year. In Ghana there are 1600 fatalities annually (Appiah, 2009). Road traffic injuries are currently ranked ninth globally among the leading causes of disease burden, in terms of Disability Adjusted Life Years (DALYs) lost (Odero, 2006). In the United States, the American Automobile Association estimates that road traffic accidents claim a life every thirteen minutes (Zheng, 2006). In Ghana 4 people get killed daily (Appiah, 2009).In many developing countries, where there is a significant increase in vehicle traffic combined with poor road infrastructure, inadequate training of drivers, and a lack of good police control, the traffic injuring rates are enormous. Road traffic crashes are known to be a leading cause of deaths and injuries in Ghana in the past decade (Afukaar et al., 2003).The majority of road traffic fatalities occurs on roads in rural areas. In Ghana about $58 \%$ more people die on roads in the rural areas than in urban areas, and generally more severe crashes occur on rural roads compared with urban areas (Afukaar et al., 2003). Considering the fact that about $70 \%$ of the population in Ghana lives in rural areas, coupled with the fact that the majority of the rural residents are engaged in agricultural activities that supports the economy of the country, it is evident that these accidents and their consequences affect the food supply and the economy of the nation.

\section{Modelling, Simulation And Data Extraction}

This chapter deals with modeling a friction damper, the simulation of the damper response and data extraction from the simulation for design purposes. The chapter presents the Maxwell, Kelvin and two Hybrid Models for the bumper. It also presents visual simulation software and discusses how it was used to program and simulate the friction damper. It then focuses on how the simulation software was used to 
generate the relevant information. ANSYS 14.0 is also used to post-process the data generated from the visual simulation.

\subsection{Modeling of Impact Attenuators}

The bumpers of most vehicles are made basically of viscous-elastic materials Huang, 2002). Properties of viscous-elastic materials include:

- Creep: increase in strain with time when the applied stress is kept constant.

- Relaxation: decrease in stress with time when the applied strain is kept constant.

- Dependence of the effective stiffness on the strain rate.

- Loss of energy due to hysteresis and

- Coefficient of restitution that is less than one.

In modeling the bumper, there is the need to address this behavior. The loss and storage of energy as well as creep and relaxation phenomena are usually modeled with spring and dashpot elements. The two main simple models that can address these are known as the Maxwell and Kelvin Models. Both models make use of a spring and a viscous damper. On the other hand a hybrid of the two, called the Solid or the Hybrid Model is also used to model this behavior. The elements of the model can be arranged in two different ways, giving two types of Hybrid models; the Hybrid 1 and Hybrid 2 models (Huang, 2002).

\subsection{The Maxwell Model}

The Maxwell Model consists of a spring and a damper connected in series. The elements of the model are considered to be mass less and uni-axial.


(c)

Fig 3.1 Schematic of a Kelvin Model and its Free Body Diagram

\subsection{The Hybrid 1 Model}

Two types of hybrid models were considered, Hybrid 1 model and Hybrid 2 model. The Hybrid models combine the Kelvin and Maxwell models making use of two springs and a dashpot. Hybrid 1 model combines a spring $k 1$ in parallel with the Maxwell model. 


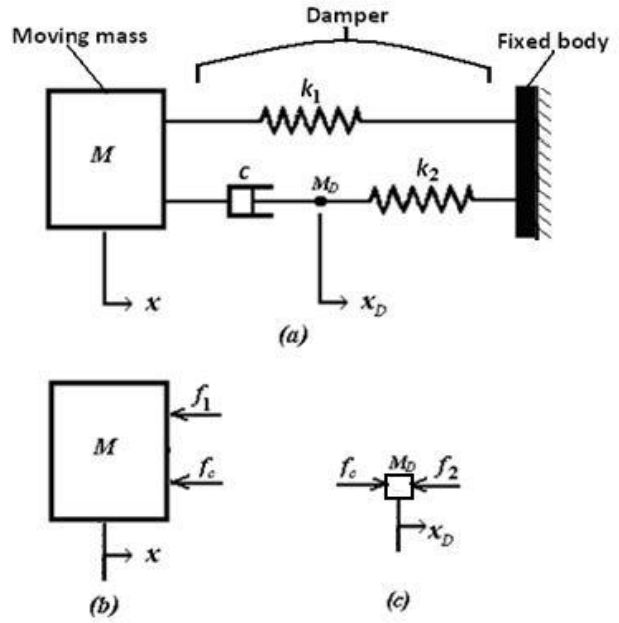

\subsection{The Hybrid 2 Model}

Figure 3.2 Hybrid 1 Model and its Free Body Diagrams

The second hybrid model, Hybrid 2 model also combines two springs with a dash pot. It combines the Kelvin model in series with a spring.

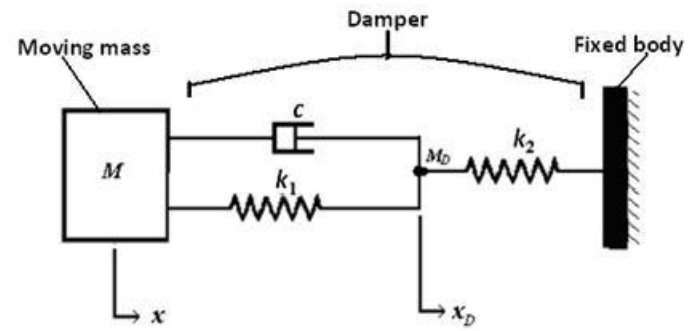

(a)

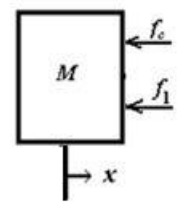

(b)

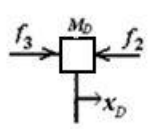

(c)

Figure 3.3 Hybrid 2 Model and its Free Body Diagrams

\subsection{Simulation}

This section discusses the responses of displacement, velocity and acceleration of the four models in line with desired behavior to evaluate them, and select the most appropriate one for further analysis. These graphs are compared with a plot of a standard crash test data used by U.S. automobile manufacturers, the New Car Assessment Program (NCAP) test, for evaluation. NCAP was established by the United S t a te s National Highway Traffic Safety Administration (NHTSA), an integral part of the United States Department of Transportation (DOT), to enhance occupant safety by generating market demand for safety features and performance that go beyond United States Federal requirements. For example for the barrier test, NCAP test was conducted at $56 \mathrm{~km} / \mathrm{h}(15.6 \mathrm{~m} / \mathrm{s}$ or $35 \mathrm{mph})$, rather than 48 $\mathrm{km} / \mathrm{h}(13.3 \mathrm{~m} / \mathrm{s}$ or $30 \mathrm{mph})$ as required by United States federal regulations (FMVSS No. 208); (NHTSA, 2007) this is done to prove to consumers that the automobile manufacturers use higher standards than that required by the law.

\subsection{Simulation and Post Processing Software}

There are several different ways of solving differential equations by numerical methods. Various software have been developed for this purpose that are available on the market. For this study, one such software, VisSim ${ }^{\mathrm{TM}}$ was selected. VisSim $^{\mathrm{TM}}$ is a programming language and development tool developed by Visual Solutions Inc. that uses block diagram language for creating complex linear and nonlinear 
dynamic systems for the modeling and simulation of simple and complex dynamic systems. VisSim ${ }^{\mathrm{TM}} \mathrm{h}$ as an intuitive drag-and-drop block diagram interface with a powerful simulation (mathematical) engine. The use of its visual block diagram interface offers a simple method for constructing, modifying and maintaining simple to complex system models. It has an extensive tool kit, a model library, and a good interface capability with a number of programming software's and was therefore found appropriate for this study.

\subsection{Justification for Selection of Kelvin Model}

The Maxwell model was ruled out as being not suitable for the modeling in this study. For the three remaining models, the Kelvin model gives a second order differential equation which is simpler and easier to solve than the hybrid ones that give third order differential equations. The limitation of the Kelvin model, however, is that it produces a non-zero deceleration at time zero, a deviation from a crash pulse, which is typically zero at time zero. However, in spite of the non-zero initial value in the acceleration, the Kelvin model's pulse duration, and rebound velocities do not deviate much from those of the Hybrid models. From Table 3.6 it deviates by a maximum of $0.01 \mathrm{~s}$ from Hybrid 1 model at design points 2 and 3 , and a maximum of $0.06 \mathrm{~s}$ from Hybrid 2 model at design point 2. Therefore the effect of the non-zero value of the acceleration at time zero is not very significant in the range of material properties under consideration. The Kelvin model shows an overall better responsiveness to changes in material properties in the material property range under study with respect to displacement, velocity and acceleration. It has a simpler solution as compared to those of the Hybrid models. Adding a friction damper to the Kelvin model will give a relatively simpler model equation than adding it to a Hybrid model.

\section{Results And Discussion}

The definitions of some terminologies used are also given in this chapter. Finally, the results from experiments are also presented to validate the simulation results. The results are mainly presented as plots of graphs after post processing.

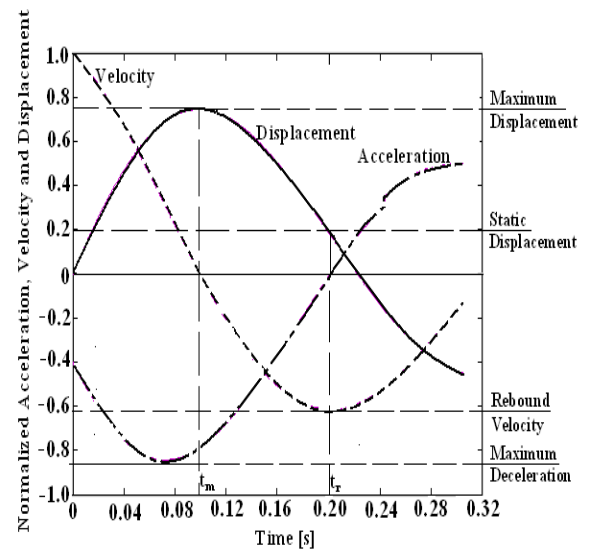

Fig 4.1 Normalized Response of a car to a Crash Pulse

\subsection{Deformation}

The effect of a friction element on the displacement of the $1900 \mathrm{~kg}$ moving mass was studied. Different friction elements were introduced, and simulations performed using a bumper-damper system with material stiffness $k$ of $542.7 \mathrm{kN} / \mathrm{m}$, and damping coefficient $c$ of $11.5 \mathrm{kN} . \mathrm{s} / \mathrm{m}$. Starting with friction force of $0 \mathrm{kN}$, simulation was performed to record the displacement responses using different impact velocities. 


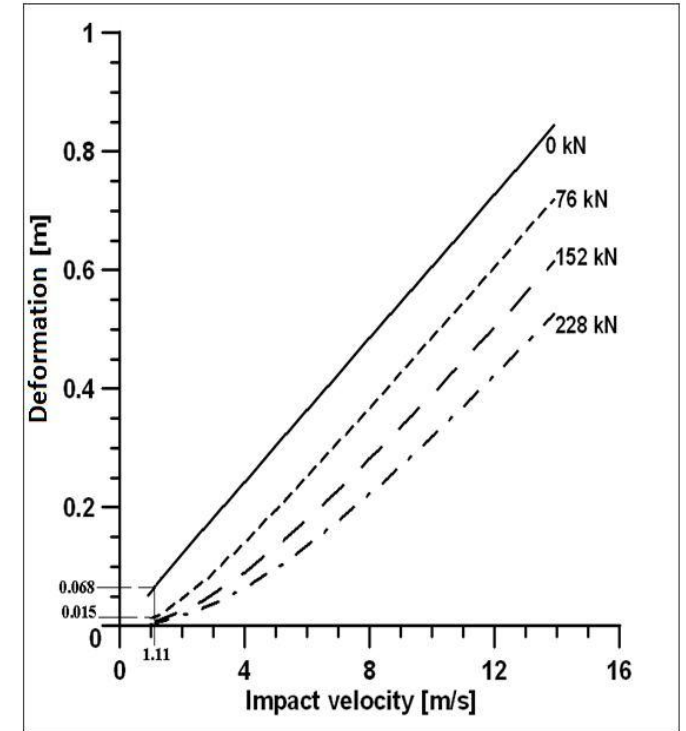

Figure 4.2 Deformation for different Friction Elements

\subsection{Work Done}

The work done by bumpers of different design materials studied were deduced from plots of impact force against the displacement for the bumpers for different friction elements. Figure 4.8 shows the responses using a friction element with $152 \mathrm{kN}$ friction force and Figure 4.9 shows the responses using a $228 \mathrm{kN}$ friction element. The work done by the bumper materials for the same amount of deformation was calculated for each case.

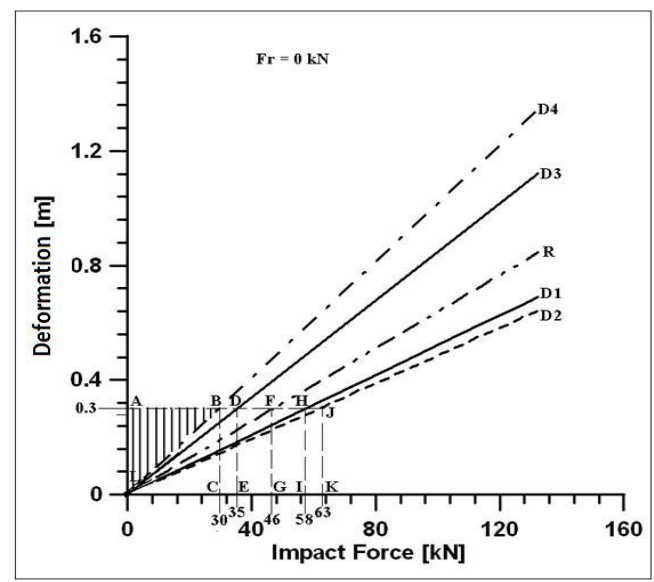

Fig 4.3 Maximum deformation of five Bumper materials at different Impact

\subsection{Friction Damper Design Concepts}

Four different friction damper concepts were put forward and one was selected for an in-depth study. Figures $4.10-4.18$ show the concepts considered. Concept 1 is shown in Figures 4.10 and 4.11. It consists of a split stationary outer hollow cone with a mating cone carrying friction lining. 



Fig 4.4 Orthographic Views of Concept

\section{Conclusion}

The focus of this dissertation has been to study and propose design parameters for a damper to attenuate impact energy of colliding road vehicles. The sedan or saloon car of a gross weight of $1900 \mathrm{~kg}$ was used for the study. The bumper of the vehicle as a crash energy attenuation component was selected and a mathematical model developed for it. The mathematical model was used to simulate impact phenomena up to relatively medium speeds of $50 \mathrm{~km} / \mathrm{h}(13.9 \mathrm{~m} / \mathrm{s})$.Investigation of the dynamics of the model revealed that with the addition of a friction damper, the energy absorption capacity of the bumper was enhanced by about $26 \%$ for the experiment with friction force of $1.14 \mathrm{kN}$ and $146 \%$ for the simulation of the bumper material $R$ with a damper supplying a frictional force of $228 \mathrm{kN}$. The vehicle with a crash impact velocity of about $3 \mathrm{~m} / \mathrm{s}$ could suffer the same amount of deformation as that experienced by a bumper without the proposed damper at $1.11 \mathrm{~m} / \mathrm{s}$. It was also observed that the deformation on the bumper without a damper caused by impact velocities up to $1.5 \mathrm{~m} / \mathrm{s}$ was the same as that caused by about three times the impact velocity, about $4.5 \mathrm{~m} / \mathrm{s}$, on the bumper with a damper with friction force 228 $\mathrm{kN}$. Design parameters were derived for bumpers that could attenuate more energy. With the bumper design parameters proposed, namely stiffness, coefficient of damping and the friction necessary in the damper to be attached, the energy absorption capacity of the bumper was improved.

\section{Future Work}

For further research the following are recommended:

$>$ Use of friction elements with higher coefficient of friction in future damper designs.

$>$ Find the stiffness of bumpers experimentally, and using the values to simulate impact phenomena to compare the results for better comparison.

$>$ Find material properties and characteristics that can operate within a wider impact velocity range.

\section{References}

[1] AASHTO (2001). A Policy on Geometric Design of Highways and Streets: American Association of State Highway and Transportation Officials, Washington D.C

[2] Abe, G. and Richardson, J. (2006). Alarm timing, trust and driver expectation for forward collision warning systems: Applied Ergonomics; 37: 577-586.

[3] Afukaar, F. K., ANTWI, P. and Ofosu-Amaah, S. (2003). "Pattern of Road Traffic Injuries in Ghana: Implications for Control." Injury Control and Safety Promotion 10 (1-2): p. 69-76.

[4] Aiken, I. D., Nims, D. K. Whittaker, A. S. and Kelly, J. M. (1993), Testing of

[5] Passive Energy Dissipation Systems: Earthquake Spectra, v. 3 
[6] Appiah, N. J. (2009) "Implementing a Decade of Action in Africa: Examples of Road Safety Interventions." National Road Safety Commission, Ghana, Make Roads Safe Conference, Dar es Salaam, Tanzania. (8-10 July, 2009).

[7] Avery, M. and Weekes, A. M. (2006), The development of a new low speed impact test to improve bumper performance and compatibility, ICrash, Athens, Greece.

[8] Aylor, D., Ramirez, D. L., Brumbelow, M. and Nolan, J. M. (2005). "Limitations of current bumper designs and potential improvements." SAE Technical Paper Series 1 (2005-01-1337).

[9] Baker, B. C., Nolan, J. M. O’Neill, B. and Genetos, A. P. (2007), Crash compatibility between cars and light trucks: Benefits of lowering front-end energy-absorbing structure in SUVs and pickups, Arlington, VA, United States, Insurance Institute for Highway Safety.

[10] Beer, F. P., Russel, E., Johnston, Jr. and DeWolf, J. T. (2006.). Mechanics of

[11] Materials. New York, McGraw-Hill.

[12] Brideson, A. R., B. Aitken, Douglas, A. and Grogan, L. (2001). Report of the Road Safety Committee on the Inquiry into Victoria's Vehicle Roadworthiness System, in R. S. Committee, ed., Australia, Victoria Parliament

[13] BRRI (2006), Estimation of cost of road traffic accidents in Ghana 